\title{
Article
}

\section{Extent of Mesoappendix of Vermiform Appendix in Bangladeshi People}

\author{
Rahman MM ${ }^{1}$ Khalil M${ }^{2}$ Khalil $M^{3}$ Sultana SZ ${ }^{4}$ Mannan $S^{5}$ Nessa A $^{6}$ Ahamed MS ${ }^{7}$ Parvin B ${ }^{8}$ Islam \\ $\mathrm{MT}^{9}$, Siddiquee $\mathrm{FS}^{10}$
}

Background: The mesentery of the appendix extends almost to the appendicular tip along the whole tube or may not be to the tip. The mesoappendix has a free border which carries the blood supply to the organ. Failure of the mesoappendix to reach the tip probably reduces the vascularization of the tip of the organ making it more liable to become gangrenous and hence early perforation occurs during inflammation. Objective: This cross sectional study was carried out to advance our knowledge regarding the extent of mesoappendix in Bangladeshi people and also to find out the variations in the anatomical positions of the vermiform appendix in Bangladeshi population and their distribution according to the sex. Methods: A total of 100 ( 60 male and 40 female) specimens of vermiform appendix were collected of different age and sex during postmortem examination in the morgue of Mymensingh Medical College from July 2006 to June 2007. Data was collected by convenient sampling technique. Results: In this study pelvic position of the vermiform appendix were common in both sexes. The two thirds extension of mesoappendix was found in $45 \%$ cases where as in pelvic position it was 26 (14 male and 12 female) cases. Half and whole extension of mesoappendix were found in $31 \%$ and $24 \%$ cases respectively. Among half extension of mesoappendix, retrocaecal position were found to be more (12) than other positions. In whole extension of vermiform appendix pelvic position were found to be common (16) than others. Conclusion: This study provides certain basic information of extent of mesoappendix of vermiform appendix of Bangladeshi population which is responsible for vascularization of the organ and severity during inflammation.

Key words: Vermiform appendix, Mesoappendix

J Bangladesh Soc Physiol. 2009 June; 4(1): 20-23 For author affiliations, see end of text.

http://www.banglajol.info/index.php/JBSP

\section{Introduction}

$\mathbf{T}$ he appendix is a caecal diberticulum appears $8^{\text {th }}$ week of intrauterine life and increases rapidly in length, so that at birth it is a long blind tube. The appendix has short mesentery called the mesoappendix ${ }^{1}$. The mesoappendix is a triangular peritoneal fold which invests the entire appendix and is derived from the posterior (left) layer of the mesentery of the ileum. Appendix is connected by a short mesoappendix to the lower part of ileal mesentery.
The mesentery of vermiform appendix hangs from the terminal part of the ilium. The mesentery of the appendix extends almost to the appendicular tip along the whole tube or may not be to the tip $^{2}$. A small fold of peritoneum extends from the terminal ileum to the front of the mesoappendix, called ileocaecal fold or bloodless fold of Treveres, although it sometimes contains blood vessels and the space between it and mesoappendix is the inferior ileocaecal recess.

J Bangladesh Soc Physiol. 2009 June; 4(1): 20-23 
Extent of Mesoappendix of Vermiform Appendix in Bangladeshi People

Article

Another fold lies in front of the teminal ileum, between of the base of the mesentery and the anterior wall of the caecum. The fold is raised up by the contained anterior caecal artery and is called the vascular fold of the caecum. The space behind it is the superior ileocaecal recess. The mesoappendix has a free border which carries the blood supply to the organ. Failure of the mesoappendix to reach the tip probably reduces the vascularization of the tip of the organ making it more liable to become gangrenous and hence early perforation occurs during inflammation. In childhood, the mesoappendix is so transparent that the contained blood vessels can be seen. In many adults it becomes laden with fat, which obscure these vessels. Its layers enclose blood vessels, lymph vessels, nerves and a single lymph node ${ }^{2}$. Mesoappendix appear at $8^{\text {th }}$ week of intrauterine life with the appearance of appendix and its extension occur after birth by differential growth of caecum ${ }^{3}$. The extent of mesoappendix not related with age, height and weight of the person ${ }^{4}$. With these in mind, the present study was done to establish a Bangladeshi standard regarding extent of mesoappendix of vermiform appendix and anatomical position of vermiform appendix.

\section{Methods}

This cross sectional study was conducted on dead bodies received in the morgue of Mymensingh Medical College from July 2006 to June 2007. Data were collected during postmortem examination using a structured format by convenient sampling technique. In this study one hundred vermiform appendix of both sexes(male60 , female-40) were observed in situ dead bodies during post mortem examination. Vermiform appendix of the decomposed dead bodies \& bodies with lacerated wounds involving appendix were not included in the study. The abdomen was opened by midline incision and the position of the vermiform appendix was observed in situ and the anatomical position was noted on the format. The caecum along with the vermiform appendix was excised. The specimens were than cleaned and washed and the extent of

J Bangladesh Soc Physiol. 2009 June; 4(1): 20-23 mesoappendix was studied and recorded on the format.

\section{Results}

A total of 100 cases in order to observe the changes in vermiform appendix due to age, collected specimens were grouped according to the age. Age and sex distribution of cases are given in the Table I.

Table I: Age and sex distribution of subjects

\begin{tabular}{lccc}
\hline Age (yrs) & \multicolumn{2}{c}{ No. of sex } & Total \\
\cline { 2 - 3 } & Male & Female & \\
\hline Upto 20 & 13 & 15 & 28 \\
$21-35$ & 28 & 11 & 39 \\
$36-55$ & 9 & 8 & 17 \\
$56-70$ & 9 & 7 & 16 \\
\hline Total & 59 & 41 & 100 \\
\hline
\end{tabular}

In both sexes pelvic position of the vermiform appendix were found to be common, shows in table II.

Table II: Distribution of the subjects by sex and anatomical position of the appendix

\begin{tabular}{lcc}
\hline Position of appendix & Male & Female \\
\hline Retrocaecal & 13 & 8 \\
Retrocolic & 6 & 5 \\
Pelvic & 29 & 22 \\
Post-ileal & 9 & 1 \\
Pre-ileal & 2 & 5 \\
\hline
\end{tabular}

The two-thirds extension of mesoappendix was found in $45 \%$ cases where as it was 26 (14 male and 12 female) in pelvic position. Half and whole extension of mesoappendix were found in 31\% and $24 \%$ cases respectively. Among half extension of mesoappendix, retroceacel position were found to be more (12) than other positions. The whole extension of vermiform appendix in pelvic position was found to be common (16) than others (Table III). 
Article

Extent of Mesoappendix of Vermiform Appendix in Bangladeshi People

Table III: Distribution of the extent of mesoappendix by sex and by anatomical position of the vermiform appendix

\begin{tabular}{|c|c|c|c|c|c|c|c|c|c|}
\hline \multirow[t]{2}{*}{ Position of VA } & \multicolumn{3}{|c|}{ 2/3 extension } & \multicolumn{3}{|c|}{$1 / 2$ extension } & \multicolumn{3}{|c|}{ Whole extension } \\
\hline & M & $\mathrm{F}$ & $\mathrm{T}$ & M & $\mathrm{F}$ & $\mathrm{T}$ & $\mathrm{M}$ & $\mathrm{F}$ & $\mathrm{T}$ \\
\hline R. caecal & 6 & 1 & 7 & 6 & 6 & 12 & 1 & 1 & 2 \\
\hline R. colic & 1 & 1 & 2 & 1 & 2 & 3 & 4 & 2 & 6 \\
\hline Pelvic & 14 & 12 & 26 & 5 & 4 & 9 & 10 & 6 & 16 \\
\hline Post ileal & 6 & 0 & 6 & 3 & 1 & 4 & 0 & 0 & 0 \\
\hline Pre ileal & 2 & 2 & 4 & 0 & 3 & 3 & 0 & 0 & 0 \\
\hline Total & 29 & 16 & 45 & 15 & 16 & 31 & 15 & 9 & 24 \\
\hline
\end{tabular}

\section{Discussion}

The appendix is supplied by a small artery that doses not anastomose with other arteries. The blind end of the appendix is supplied by the terminal branches of the appendicular artery. Inflammatory oedema of the appendicular wall compresses the blood supply to the appendix and often leads to thrombosis of the appendicular artery. These conditions commonly result in necrosis or gangrene of the appendicular wall, with perforation ${ }^{5}$

In this study pelvic position of the vermiform appendix were found to be common in both sexes. The present study, observed that two-thirds and whole extension of the mesoappendix were more common in male and it was also common in pelvic variety.

In this study the extent of mesoappendix to twothirds length of vermiform appendix was $45 \%$ and most common in pelvic variety positions. The extent of mesoappendix to $1 / 2$ length of vermiform appendix was $31 \%$ and common in retrocaecal positions. Whole extension of mesoappendix in the vermiform appendix was $24 \%$ and it was common in pelvic variety. These findings are in consistent with the study of Bakheit and Bergmann where 2/3 extension of mesoappendix were found to be more (43\%) common in pelvic variety and $1 \frac{1}{2}$ extension mesoappendix were more (40\%) common retrocaecal position of vermiform appendix ${ }^{6,7}$.

The present study also found that $2 / 3$ extension is more than $1 / 2$ and whole extension of mesoappendix.

Failure of the mesoappendix to reach the tip probably reduces the vascularization of the tip of the organ making it more liable to become gangrenous and hence early perforation during inflammation ${ }^{8}$.

\section{Conclusion}

By reviewing the findings of the study, pelvic variety of the appendix were found to be common. Pelvic position was common in $2 / 3$ and whole extension of the mesoappendix where as the recto-caecal was common in $1 / 2$ extension of mesoappendix. It was also found that $2 / 3$ extension is more that $1 / 2$ and whole extension of mesoappendix. As extension of mesoappendix is responsible for vascularization of the vermiform appendix and severity during inflammation, so the finding of the study e.g. 2/3 extension was more than others provide an important information.

J Bangladesh Soc Physiol. 2009 June; 4(1): 20-23 


\section{Authors affiliations}

1. *Dr. Md. Mahbubur Rahman, Assistant Professor (cc), Department of Anatomy, Mymensingh Medical College

2. Professor Dr. Mohsin Khalil, Professor \& Head of the Department of Anatomy, Mymensingh Medical College.

3. Professor Dr. Mansur Khalil, Professor \& Head of the Department of Anatomy, Chittagong Medical College.

4. Dr. Seheli Zannat Sultana, Associate Professor, Department of Anatomy, Mymensingh Medical College.

5. Dr. Sabina Mannan, Assistant Professor, Department of Anatomy, Mymensingh Medical College.

6. Dr. Akhtarun Nessa, Assistant Professor Department of Physiology, Mymensingh Medical College.

7. Dr. M. Shibbir Ahamed, Lecturer, Department of Anatomy, Mymensingh Medical College.

8. Dr. Bilkis Parvin, Medical officer, Mymensingh Medical College Hospital

9. Dr. Md. Tarequl Islam, Medical officer, Jamalpur Sadar Hospital

10. Dr. Fayela Sabrun Siddiquee , Assistant Registrar, Gynae \& Obs 1

* For correspondence

\section{References}

1. Sinnatamby CS, Last's anatomy Regional and Applied, $10^{\text {th }}$ ed. Churchill Living stone: Edinburgh; $1999 \mathrm{p}-249-50$.

2. Schwartz SI, Principles of surgery, $7^{\text {th }}$ ed, McGrawHill, International edition health profession Division: 1998, p. 1383-93.

3. Ross MH, Koye GI, Pawlina W, editors. Histology: A text and atlas, $5^{\text {th }}$ ed. Baltimore: Willims and Wilkins; 2005. P. 528-574.

4. Snell RS. Clinical Anatomy. $7^{\text {th }}$ ed. Baltimore: Lippincott William and Wilkins; 2004. P. $215-7$.

5. Borley NR. Editor, Microstructure of the large intestine. In: Berkovitz KBB, Borley NR, Crossman AR, Davis MS, Fitzgerald MJT, Glass J, et. al editors. Grays anatomy: the anatomical basis of clinical practice. $39^{\text {th }}$ edi, Edinburgh: Elsevier Churchill Livingstone; 2005, P. 1173-86.

6. Bakheit MA, Warille AA. Anomalies of the vermiform appendix and prevalence of the acute appendicitis in Khartoum. King Faisal University, Dammam, Saudi Arabia. East Afr Med J, 1999; June; 76 (6): 338-40.

7. Bergmann J. Do any vestigial structures exists in humans? CEN Technical Journal 14 (2) 2000.

8. Das S. A concise Text book of surgery. $1^{\text {st }}$ ed. Calcutta; S.D. Publishers; 1996, P.966. 